\title{
Structural, Surface Morphology and Optical Properties of Pulsed Laser Deposited ZnO Thin Films at Various Laser Pulse Energies
}

\author{
Ying Huang ${ }^{1, a}$, Jia Yuan Qin ${ }^{1, b}$, Xiao Ming Shen ${ }^{1, c^{*}}$, Nguyen Manhtai ${ }^{2}$, Yue \\ Chun $\mathrm{Fu}^{1}$, Huan $\mathrm{He}^{1}$, Shu Long $\mathrm{Lu}^{2}$ and Li Feng Bian ${ }^{2}$ \\ ${ }^{1}$ Key Laboratory of New Processing Technology for Materials and Nonferrous Metal, Ministry of \\ Education, College of Material Science and Engineering, Guangxi University, Nanning 530004, \\ China
}

${ }^{2}$ Key Laboratory of Nanodevices and Applications, Suzhou Institute of Nano-Tech and Nano-Bionics, Chinese Academy of Sciences, Suzhou 215123, China

ahyamps@163.com, b1549496234@qq.com, docsjh@gxu.edu.cn

Keywords: $\mathrm{ZnO}$ thin films, pulsed laser deposition, optical properties, laser pulse energy

Abstract. $\mathrm{ZnO}$ thin films have been deposited on ITO substrates by pulsed laser deposition at various laser pulse energies. The crystalline structure, surface morphology and optical properties of $\mathrm{ZnO}$ thin films were characterized by X-ray diffraction (XRD), atomic force microscope (AFM) and UV-Visible measurements. The results showed that $\mathrm{ZnO}$ thin films grew along with (002) preferential orientation and had optimal crystalline quality when laser pulse energy kept in $180 \mathrm{~mJ} \cdot \mathrm{P}^{-1}$. In addition, the films had smooth surface and compacted structure. Laser pulse energy had little influence on the transmittance of $\mathrm{ZnO}$ thin films in visible light region and the transmittance of all the $\mathrm{ZnO}$ thin films is above $80 \%$. It also can be found that the film thickness and optical band gap increased with the increase of laser pulse energy from $150 \mathrm{~mJ} \cdot \mathrm{P}^{-1}$ to $200 \mathrm{~mJ} \cdot \mathrm{P}^{-1}$.

\section{Introduction}

$\mathrm{ZnO}$ is a semiconductor material with a direct wide band gap $(\sim 3.37 \mathrm{eV})$, and have a wide range of promising applications for solar cells, light emitting diodes, transparent electrodes and UV photodetector, due to its outstanding optical properties, high exciton binding energy, excellent thermal stability and low cost [1]. Although $\mathrm{ZnO}$ has lots of excellent properties, the abundance of defects in $\mathrm{ZnO}$ is an impediment for wide application [2]. Nowadays, there are many different methods to prepare $\mathrm{ZnO}$, such as magnetron sputtering [3], sol-gel coating [4], chemical vapor deposition (CVD) [5], pulsed laser deposition (PLD) [6] and spray pyrolysis [7].To achieve high quality $\mathrm{ZnO}$ thin films, we use pulsed laser deposition which have advantage of simple operation, low substrate temperature and good consistency of film and target composition.

In this paper, $\mathrm{ZnO}$ thin films were deposited on ITO substrates by pulsed laser deposition at various laser pulse energies. The effects of laser pulse energy on structural, surface morphology and optical properties of $\mathrm{ZnO}$ thin films were investigated.

\section{Experimental}

$\mathrm{ZnO}$ thin film was deposited on ITO substrate by LMBE-450 pulsed laser deposition system. Prior to the deposition, the ITO substrates were ultrasonically cleaned sequentially in acetone, ethyl alcohol and de-ionized water for 5 min, respectively. A pure ceramic $\mathrm{ZnO}$ target (99.99\%) was used to deposit $\mathrm{ZnO}$ thin films, and the substrate was placed $4 \mathrm{~cm}$ away from the $\mathrm{ZnO}$ target. The base pressure was pumped down to $10^{-5} \mathrm{~Pa}$, and the substrate was heated to $473 \mathrm{~K}$. During the growth of $\mathrm{ZnO}$ thin film, oxygen gas $(99.999 \%$ purity) was introduced into the deposition chamber 
to reach a working pressure of $0.8 \mathrm{~Pa}$. Laser pulse energy was varied from $150 \mathrm{~mJ} \cdot \mathrm{P}^{-1}$ to $200 \mathrm{~mJ} \cdot \mathrm{P}^{-1}$ ( KrF excimer laser beam, $1 \frac{1 / 4}{4} 248 \mathrm{~nm}$ and n $1 / 45 \mathrm{~Hz}$ ). All depositions were carried out for $60 \mathrm{~min}$.

The crystalline phase analysis of $\mathrm{ZnO}$ thin films was identified by X-ray diffraction (Rigaku D/MAX 2500) using $\mathrm{Cu} \mathrm{K \alpha}$ radiation $(\lambda=0.154 \mathrm{~nm})$, the source being operated at $40 \mathrm{kV}$ and $40 \mathrm{~mA}$. The surface morphology of films was studied by Agilent 5500 atomic force microscope. The optical transmission was measured by PerkinElmer Lambda 950 UV-Vis-NIR spectrophotometer along with $150 \mathrm{~mm}$ integrating sphere.

\section{Results and discussion}

Fig. 1 shows XRD patterns of ITO substrate and $\mathrm{ZnO}$ thin films deposited at various laser pulse energies. The absence of $\mathrm{ZnO}$ thin films peaks at $2 \theta$ in the XRD pattern were $34.8^{\circ}$ and $63.2^{\circ}$, corresponding to the Miller indexes of the reflecting planes of hexagonal wurtzite $\mathrm{ZnO}(002)$ and (103) (JCPDS no.36-1451). ZnO thin films show a (002) preferential orientation and a weak (103) orientation. As the laser pulse energy increases from $150 \mathrm{~mJ} \cdot \mathrm{P}^{-1}$ to $180 \mathrm{~mJ} \cdot \mathrm{P}^{-1}$, the relative intensity of the peak in (002) plane increase for $\mathrm{ZnO}$ thin films while it decrease for $\mathrm{ZnO}$ thin films on elevating laser pulse energy from $150 \mathrm{~mJ} \cdot \mathrm{P}^{-1}$ to $180 \mathrm{~mJ} \cdot \mathrm{P}^{-1}$.

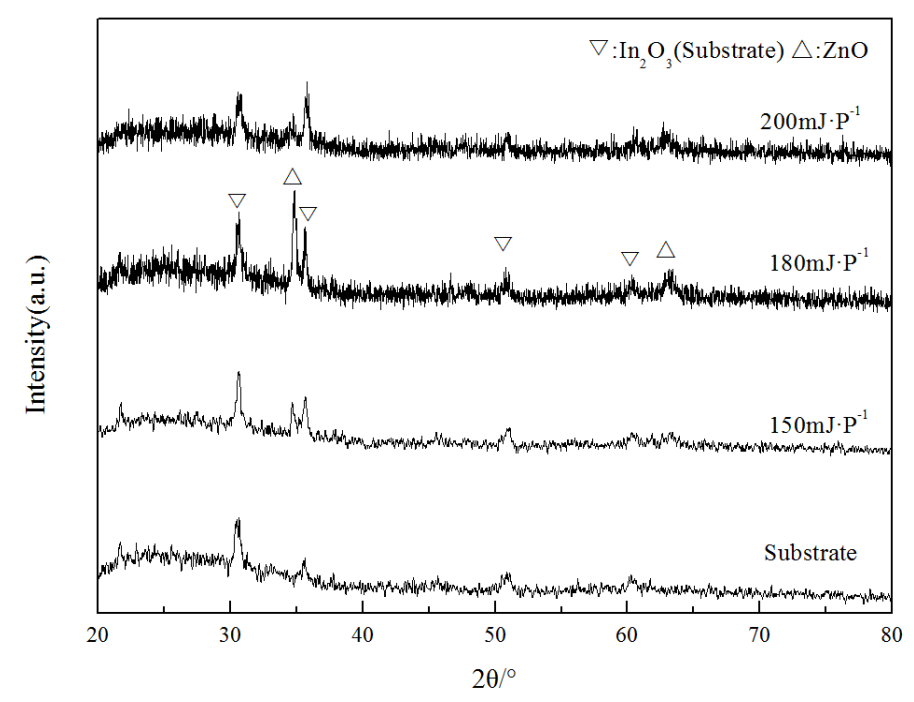

Fig. 1 XRD patterns of ITO substrate and ZnO thin films deposited at various laser pulse energies

AFM patterns of $\mathrm{ZnO}$ thin films deposited at various laser pulse energies are illustrated in Fig. 2, revealing that a grain size is $80 \sim 160 \mathrm{~nm}$. The superficial roughness was given in Table 1 . While $\mathrm{ZnO}$ deposited at $150 \mathrm{~mJ} \cdot \mathrm{P}^{-1}$ to $180 \mathrm{~mJ} \cdot \mathrm{P}^{-1}$, the films has smooth surface and compacted structure. However, $\mathrm{ZnO}$ thin films have lots of voids between relatively isolated grains at $200 \mathrm{~mJ} \cdot \mathrm{P}^{-1}$, and the superficial roughness is much higher than $\mathrm{ZnO}$ thin films deposited at $150 \mathrm{~mJ} \cdot \mathrm{P}^{-1}$ to $180 \mathrm{~mJ} \cdot \mathrm{P}^{-1}$. 

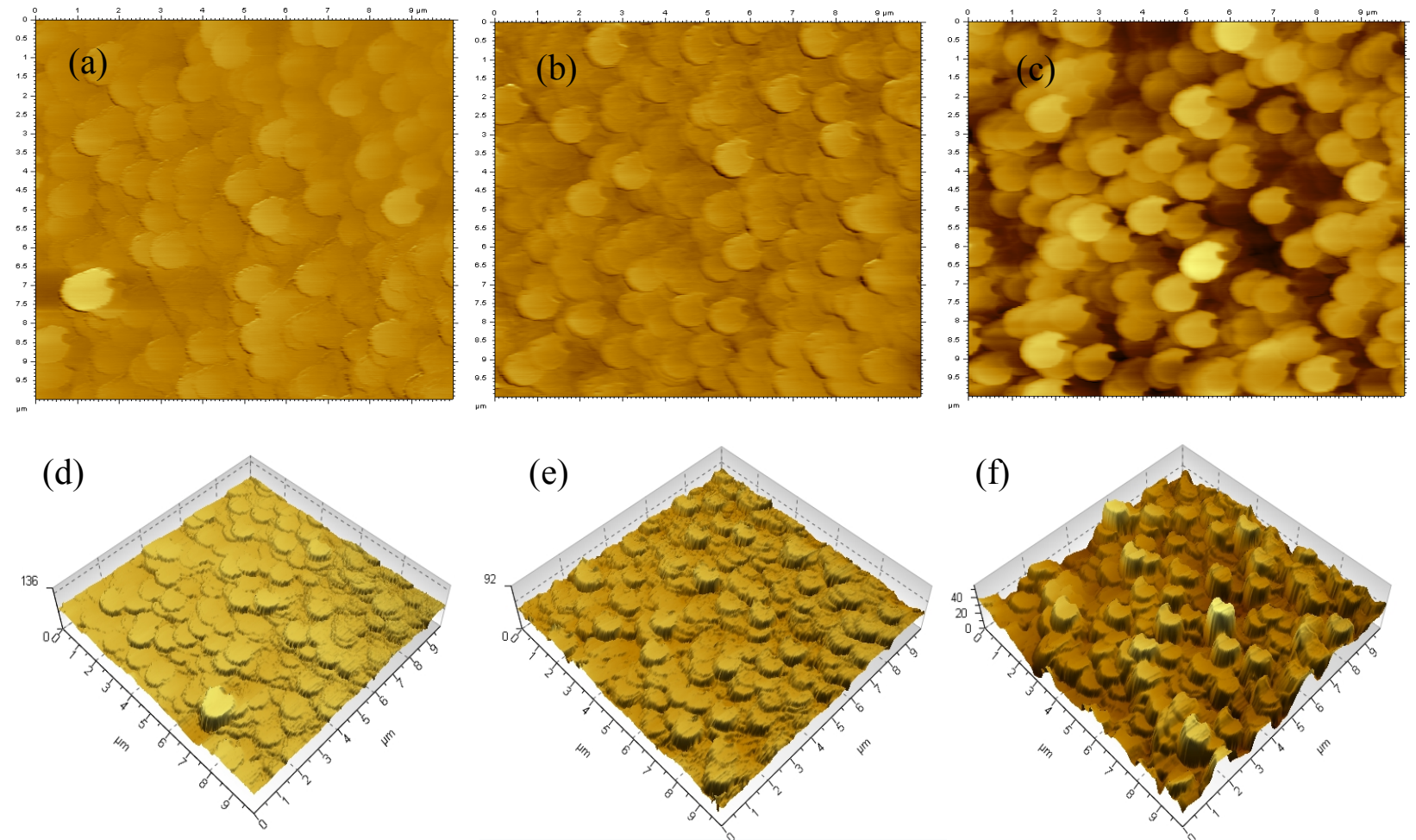

Fig. 2 AFM patterns of $\mathrm{ZnO}$ thin films deposited at various laser pulse energies $(10 \mu \mathrm{m} \times 10 \mu \mathrm{m})$
(a) and $(\mathrm{d}): 150 \mathrm{~mJ} \cdot \mathrm{P}^{-1}$
(b) and (e): $180 \mathrm{~mJ} \cdot \mathrm{P}^{-1}$
(c) and (f): $200 \mathrm{~mJ} \cdot \mathrm{P}^{-1}$

Table.1 Superficial roughness of $\mathrm{ZnO}$ thin films deposited under various laser pulse energies

\begin{tabular}{ccc}
\hline $\begin{array}{c}\text { Laser pulse energy } \\
\left(\mathrm{mJ} \cdot \mathrm{P}^{\mathbf{1}}\right)\end{array}$ & $\begin{array}{c}\text { Arithmetic mean roughness } \\
(\mathrm{nm})\end{array}$ & $\begin{array}{c}\text { Root mean square roughness } \\
(\mathrm{nm})\end{array}$ \\
\hline 150 & 3.7 & 4.9 \\
180 & 3.6 & 4.7 \\
200 & 6.2 & 7.8 \\
\hline
\end{tabular}

Fig. 3(a) shows the transmittance spectra of $\mathrm{ZnO}$ thin films deposited under various laser pulse energies. Laser pulse energies had little influence on the transmittance of $\mathrm{ZnO}$ thin films in the visible range and the transmittance of all the $\mathrm{ZnO}$ thin films is above $80 \%$. As the laser pulse energy increases from $150 \mathrm{~mJ} \cdot \mathrm{P}^{-1}$ to $180 \mathrm{~mJ} \cdot \mathrm{P}^{-1}$, the absorption edge shifts to shorter wavelength.
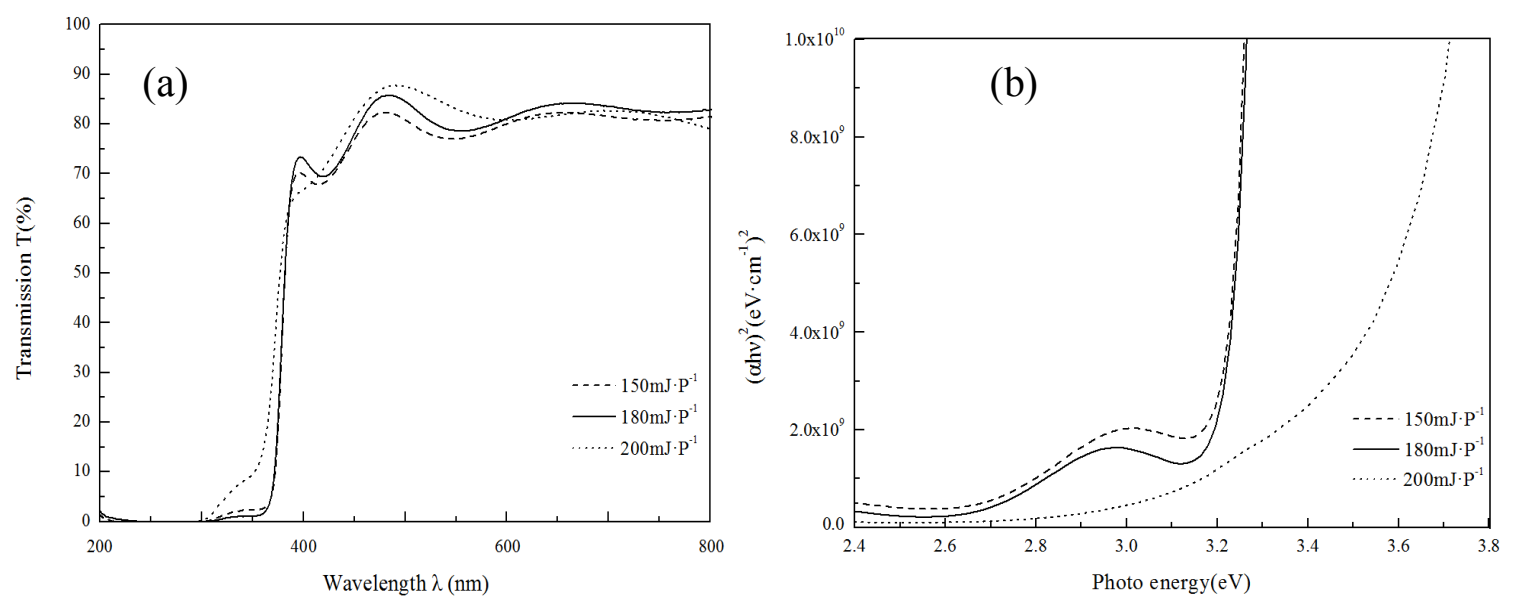

Fig.3 (a) Transmittance spectra and (b) Plots of $(\alpha h v)^{2}$ as function of photo energy of $\mathrm{ZnO}$ thin films deposited at various laser pulse energies 
Fig.3 (b) shows Plots of $(\alpha h v)^{2}$ as function of hv of $\mathrm{ZnO}$ thin films deposited at various laser pulse energies. The films thickness and the optical band gap $\left(\mathrm{E}_{\mathrm{g}}\right)$ of $\mathrm{ZnO}$ thin films, calculated by optical transmittance data, were reported in Table 2 [8]. The calculated optical band gap of the films varies between $3.19 \mathrm{eV}$ and $3.32 \mathrm{eV}$. It can be observed that the optical band gap and the film thickness increase with the increase of laser pulse energy from $150 \mathrm{~mJ} \cdot \mathrm{P}^{-1}$ to $200 \mathrm{~mJ} \cdot \mathrm{P}^{-1}$.

Table 2 Film thickness and optical bandgap energy $\left(E_{g}\right)$ of $\mathrm{ZnO}$ thin films deposited at various laser pulse energies

\begin{tabular}{ccc}
\hline Laser pulse energy $\left(\mathrm{mJ} \cdot \mathrm{P}^{\mathbf{1}}\right)$ & Film thickness $(\mathrm{nm})$ & $\mathrm{E}_{\mathrm{g}}(\mathrm{eV})$ \\
\hline 150 & 259 & 3.19 \\
180 & 268 & 3.21 \\
200 & 329 & 3.33 \\
\hline
\end{tabular}

\section{Conclusions}

In this study, the change of structural, surface morphology and optical properties of $\mathrm{ZnO}$ thin films deposited at laser pulse energy have been explored. Experimental results show that the deposited films are hexagonal wurtzite structure which has a (002) preferred growth orientation. $\mathrm{ZnO}$ thin films had better crystalline quality and smooth surface when laser pulse energy was $180 \mathrm{~mJ} \cdot \mathrm{P}^{-1}$. Films deposited at higher laser pulse energy show increased the optical band gap value of $\mathrm{ZnO}$ thin films from $3.19 \mathrm{eV}$ to $3.32 \mathrm{eV}$. Laser pulse energy had little influence on the transmittance of $\mathrm{ZnO}$ thin films in visible light region and all the $\mathrm{ZnO}$ thin films show above $80 \%$ transmittance in visible range.

\section{Acknowledgements}

This research was supported by the National Natural Science Foundation of China (Grant No.61474030), and the Open Foundation of Key Laboratory of Nanodevices and Applications, Chinese Academy of Sciences (Grant No.15ZS06).

\section{References}

[1] R. Vettumperumal, S. Kalyanaraman, R. Thangavel, J. Mol. Struct. 1059 (2014) 61-67.

[2] B. Venkateswarlu, B. S. Chandra, D. Debjit, S. Vandana, S. Keshawa, Optic. Mater. 35(2015) 1352-1359.

[3] Satyendra KumarC. Wang, Z. G. Ji, J. H. Xi, Mater. Let. 60 (2006) 912-914.

[4] C.Y. Tsay, H.C. Cheng, M.C. Wang, Surf. Coat. Tech. 202 (2007) 1323-1328.

[5] J. G. Lu, T. Kawaharamura, H. Nishinaka, Y. Kamada, T. Ohshima, S. Fujita, J. Cryst. Growth. 299 (2007) 1-10.

[6] Y.Z. Zhang, J.G. Lu, Z.Z. Ye, Appl. Surf. Sci. 254 (2008) 1993-1996.

[7] B. Godbole, N. Badera, S. Shrivastava, D. Jain, V. Ganesan, Mater. Sci. Appl. 2(2011)643-648.

[8] R. Mimouni, O. Kamoun, A. Yumak, A. Mhamdi, K. Boubaker, P. Petkova, M. Amlouk, J. Alloys. Compd. 645 (2015) 100-111. 